IJOPM

29,9

946

\section{Supply chain flexibility: an inter-firm empirical study}

\author{
Mark Stevenson and Martin Spring
}

Department of Management Science, Lancaster University Management School, Lancaster University, Lancaster, UK

\begin{abstract}
Purpose - The purpose of this paper is to present an empirical study of supply chain flexibility, asking: what specific inter-firm practices are used to achieve increased flexibility in buyer-supplier pairs and in the wider supply chain or network, and how do these practices and effects interact?

Design/methodology/approach - The approach taken is a qualitative study of a network of 16 inter-related manufacturing companies. Semi-structured face-to-face interviews with senior representatives from each company.

Findings - A wide range of supply chain flexibility practices are identified, some confirming existing research, some additional. These are grouped into ten categories, and two over-arching themes are found. First, firms use various forms of outsourcing and subcontracting to reduce their own need for internal flexibility. The second related insight is that, having externalised the need for flexibility, firms improve flexibility of the whole chain by engaging in committed relationships with counterparts. The authors term the ability to change counterparts "configuration flexibility" and the ability to change the timing, volume and design of supply "planning and control flexibility". Therefore, it is suggested that firms make complex trade-offs between the two in the interest of achieving overall supply chain flexibility. These are presented in a model to allow for future refinement and testing.

Research limitations/implications - Supply chain flexibility is a strategic objective, but is not achieved by all members of supply chains aiming for as much flexibility as possible on all dimensions. The identification of the supply chain flexibility practices provides a starting point for further theoretical developments as well as for practice. In particular, further work is required to understand the interplay between the two types of flexibility identified.

Originality/value - Study of inter-connected supply chains, model linking practices to performance, and the main notions of configuration and planning and control flexibilities.

Keywords Supply chain management, Buyer-seller relationships

Paper type Research paper

\section{Introduction}

Contemporary manufacturing is highly competitive and serves customers who increasingly demand customised products and short lead-times. Many companies that have previously relied on order-winning through low-cost, standardised production have had to become more flexible. The importance of flexibility in meeting customer

Aspects of this work have been presented to Lancaster University Management School's Supply Chain Management and Modelling Research Group (February, 2007); at the Production and Operations Management Society Conference (May, 2007); and at the European Operations Management Association Conference (June, 2007). The authors would like to thank those who attended these presentations, and those who read earlier versions of this paper, for their helpful comments. The authors would also like to acknowledge the helpful advice provided by the Guest Editors and two anonymous reviewers. The authors would also like to acknowledge the funding

of this project provided by the Lancaster University Management School.
\end{abstract}

International Journal of Operations \& Production Management

Vol. 29 No. 9, 2009

pp. $946-971$

(C) Emerald Group Publishing Limited 0144-3577

DOI $10.1108 / 01443570910986238$ 
demands is widely acknowledged (Fisher et al., 1994; Vickery et al., 1999; Olhager and West, 2002) to the extent that it is now described as a strategic capability (Lau, 1996; de Toni and Tonchia, 2005; Krajewski et al., 2005). Until recently, flexibility has been most commonly associated with the manufacturing flexibility literature of the 1980s and 1990s with seminal papers by Slack $(1983,1987)$, Gerwin $(1987,1993)$ and Upton $(1995)$. While valuable, this was restricted to studying the flexibility of manufacturing systems, cells and plants, i.e. intra-firm flexibility. Nowadays, manufacturing companies (often by choice) are becoming increasingly reliant on external sources of supply, and are increasingly aware of the need to manage and integrate the whole value chain (Fisher, 1997; Lambert et al., 1998; Croom et al., 2000; Jack and Raturi, 2002). Consequently, the need to study flexibility in a wider supply chain context, as well as at the firm level, is now being recognised (Eloranta et al., 1995; Krajewski et al., 2005; Schmenner and Tatikonda, 2005). Supply chain flexibility is highly relevant to practitioners, but empirical research in this area is limited and many authors have called for further research (Golden and Powell, 1999; Vickery et al., 1999; Lummus et al., 2005; Kumar et al., 2006). In response, this paper presents results from an empirical study into supply chain flexibility across a network of 16 inter-related UK-based manufacturing companies. The findings from this exploratory study can be used as the basis for future in-depth work and to develop theory about flexibility in a supply chain context. The remainder of the paper is organised as follows. A brief definition of flexibility and an overview of recent research are provided, then gaps in the literature are identified. The research method is then outlined. Findings are then presented, organised around ten flexibility themes from the literature and data analysis. The next section, the discussion, proposes a model that links these practice areas with two aggregate forms of supply chain flexibility - configuration flexibility and planning and control flexibility. The final section suggests some areas for further work.

\section{From manufacturing flexibility to supply chain flexibility}

Early studies defined flexibility in terms of range, mobility and uniformity, i.e. the various states a system can adopt, the ability to move from making one product to making another and the ability to perform comparably well when making any product within a specified range (Slack, 1983; Upton, 1995). Slack (1983) and Upton (1995) also note that flexibility is, in part, a measure of potential behaviour, i.e. flexibility does not have to be demonstrated in order for it to exist. Various typologies of flexibility have been proposed. Slack (1983) described five types of flexibility (new product, product mix, quality, volume and delivery). Gerwin (1987) described seven types of flexibility, while Koste and Malhotra (1999) and Narasimhan and Das (2000) extended this to ten and Vokurka and O'Leary-Kelly (2000) presented 15 (machine, material handling, operations, automation, labour, process, routing, product, new design, delivery, volume, expansion, program, production and market). The focus of much of this work is on flexibility at the firm level.

More recently, a literature on supply chain flexibility has emerged. Duclos et al. (2003) developed a conceptual model of supply chain flexibility consisting of six components, refined to five by Lummus et al. (2003). These are: operational systems, logistics processes, supply network, organisational design and information systems flexibility. A further contribution is made by Kumar et al. (2006). The flexibility types used in this literature incorporate a more explicit inter-firm element. For example,

\section{Supply chain flexibility}


IJOPM

29,9

\section{8}

logistics (processes) flexibility relates to receiving and delivering products as the sources of supply and customers change.

Beyond definitions, the emerging literature on supply chain flexibility can be split into four categories:

(1) that which begins to link a firm's flexibility to elements external to the firm;

(2) flexibility in the design of supply chains;

(3) flexibility through supply chain relationships; and

(4) flexibility through information sharing.

The following sections analyse some of the key contributions in these areas to date (for a more complete review, see Stevenson and Spring, 2007).

Linking a firm's flexibility to the wider supply chain

Survey research by Narasimhan and Das $(1999,2000)$ found that sourcing and supply chain management practices affect manufacturing flexibilities. Similarly, Vickery et al. (1999), studying the furniture industry, found a positive relationship between supply chain flexibility - particularly volume flexibility and launch flexibility - and firm performance. Sánchez and Pérez (2005) explored the relationship between supply chain flexibility and firm performance in automotive suppliers. Volume flexibility was found to be particularly important, as was the need to tailor flexibility strategy to the characteristics of a given supply chain. These studies make an important contribution by linking flexibility to the supply chain and acknowledging that the importance of components of flexibility vary from supply chain to supply chain. We argue that there is also a need to link other components of flexibility to the supply chain.

\section{Flexibility in the design of supply chains}

The design of the supply chain is important in determining the flexibility of the existing structure and the ease with which the chain can be re-configured. Modellers have contributed to this area by extending single-stage models to a multi-stage supply chain; for example, both Bertrand (2003) and Graves and Tomlin (2003) built on an earlier model of Jordan and Graves (1995). Garavelli (2003) and Aprile et al. (2005) examined the impact of process flexibility (at the firm level) and logistics flexibility with suppliers, assemblers and markets on supply chain performance. Unusually, these papers attempt to prescribe suitable degrees of flexibility, rather than suggesting, as most work in the area does, that the more flexible a supply chain is, the better. However, their relevance is reduced by the simplifications that such modelling necessarily requires. We argue that there is a need for researchers to explore the relationship between supply chain design and flexibility across networks.

\section{Supply chain relationships}

Various aspects of flexibility in buyer-supplier relationships have been explored in the literature. Modellers have focussed on flexibility in procurement contracts, which can both provide stability for the supplier and help the buyer to respond to demand fluctuations (Tsay, 1999; Sethi et al., 2004; Milner and Kouvelis, 2005). Most empirical researchers have explored "softer" aspects of supply chain relationships. For example, Suarez et al. $(1995,1996)$ examined the impact of relationships with suppliers and subcontractors on manufacturing flexibility in the printed circuit boards industry and 
found that close relationships have a positive effect on mix, volume and new product flexibility. Pérez and Sánchez (2001) studied the flexibility of buyer-seller relationships in the automotive industry, highlighting the importance of just-in-time (JIT) delivery, information sharing, trust, commitment and supplier involvement in product design. This empirical research has tended to focus on the procurement function, existing relationships and the perspective of the supplier. We argue that there is a need to conduct broader studies involving both customer and supplier perspectives.

Flexibility through information sharing and inter-firm information systems

Information sharing can improve the flexibility of the supply chain (Golden and Powell, 1999; Fredericks, 2005; Gosain et al., 2005). It can improve transparency, avoid lost sales, speed up payment cycles, create trust, avoid over-production and reduce inventories. Current inter-firm information systems and internet technologies can therefore facilitate the effective co-ordination of supply networks. Golden and Powell (1999), for example, found that supply chain flexibility depends on the extent to which data are shared through inter-organisational information systems. White et al. (2005) explored the role of e-hubs and web services in providing flexibility, and found that information systems can be used to develop deep relationships and increased flexibility. Finally, Fredriksson and Gadde (2005) described the case of Volvo cars. Their paper highlighted the importance of information sharing and showed that industry characteristics influence supply chain flexibility.

Summary of key gaps in the supply chain flexibility literature. From the above, a number of gaps in the literature emerge:

- Inter-firm analysis. While the supply chain flexibility literature considers how the chain as a whole can provide flexibility, it tends to do so from the perspective of a firm and to emphasise properties of single firms. Few attempts have been made to take a more network-oriented perspective of flexibility (Golden and Powell, 1999; Gosain et al., 2005; Krajewski et al., 2005); to date these have largely stretched only as far as first-tier relationships. Research should be conducted in which the unit of analysis is inter-firm, e.g. at the supply chain or network level (Harland et al., 1999; van Hoek et al., 2001).

- Adopting an ambivalent (open-minded) approach. Lummus et al. (2003) propose: "a positive relationship between the operations systems characteristics of each node and overall supply chain flexibility" while Duclos et al. (2003) state that "the evolution from individual organisation flexibility to cross-firm flexibility results in the requirement that entire supply chains be flexible". In much of the flexibility literature, there appears to be an assumption that the more flexible a firm or supply chain is, the better. However, practices such as outsourcing allow firms to concentrate on a narrower range of operations, i.e. in some cases there is a deliberate shift to reduce flexibility within one firm by accessing it in another. It has therefore been argued that researchers should remain ambivalent about the desirability of flexibility in every part of the system (Stevenson and Spring, 2007).

- Incorporating the roles of SMEs/upstream entities. Insufficient attention is given to small- and medium-sized enterprises (SMEs) and subcontractors, even though they often compete by specialising in flexibility, with a flexible labour force, flexible machines and less bureaucracy (Lyons and Bailey, 1993) and are

\section{Supply chain flexibility}


IJOPM

29,9

\section{0}

\section{Research methodology}

Research question

It is not the intention of this research to re-discover issues of an intra-firm nature; instead, we focus on aspects of inter-firm flexibility, i.e. flexibility that involves at least two firms. We are interested in flexibility at different levels of aggregation, especially in buyer-supplier pairs and in larger chains and networks. As such, our research question is:

$R Q$. What specific inter-firm practices are used to achieve increased flexibility in buyer-supplier pairs and in the wider supply chain or network, and how do these practices and effects interact?

Given the state of existing research and the gaps identified, this study takes a network approach, maintains an ambivalent view of flexibility and pays particular attention to the roles of SMEs/upstream entities. These aspects of the approach influence the phenomena examined and the design of the study.

\section{Research design}

We study a network of inter-related companies. This has rarely been attempted in the operations management literature, but is considered the best way of exploring flexibility in an inter-firm context. It adds to the richness of insight, allows inter-firm aspects and relations to be explored from multiple perspectives, contributes to drawing a more complete theoretical picture, and allows for the study of multiple units of analysis (i.e. firm-, dyad-, supply-chain- and network-levels).

The multi-case study method has been adopted. Given the relative infancy of the supply chain flexibility field, the research is exploratory; Voss et al. (2002) explain that "the case method lends itself to early, exploratory investigations where the variables are still unknown and the phenomenon not at all understood" (Benbasat et al., 1987; Meredith, 1998). Exploratory case study research can be an important step toward theory building (Eisenhardt, 1989; Eisenhardt and Graebner, 2007). When exploring new theory, the multi-case method can be appropriate, augment external validity, guard against observer bias (Handfield and Melnyk, 1998; Meredith, 1998; Voss et al., 2002), aid triangulation and improve the generality of findings (Voss et al., 2002; Yin, 2003). Furthermore, Eisenhardt and Graebner (2007) refer to Bartunek et al. (2006) in stating that "papers that build theory from cases are often regarded as the 'most interesting' research".

\section{Company selection process}

Choosing which, and how many, cases to study are important methodological considerations (Stuart et al., 2002; Yin, 2003). In this study, firms were selected from the supply chains of three industries:

(1) aerospace (defence and commercial);

(2) rail; and

(3) commercial vehicles (trucks). 
These actually formed a network, being joined by shared sources of supply. While researchers have explored industries such as automotives and information technology in the context of supply chain flexibility (Pérez and Sánchez, 2001; Sánchez and Pérez, 2005; Fredriksson and Gadde, 2005; White et al., 2005), the above industries have received little attention (if any). Companies were chosen if part of this network, being identified through web searches, web site content analysis, articles published in trade magazines, interviews with other members of the network and by geographical location (clusters of companies often have direct and indirect relations with one another). In addition, firms explicitly offering flexibility were targeted: for example, the web site of one of the firms studied claims: "The answer is 'Yes', what's your question? - Give us a call to see what we can do for you today" (i.e. claiming "we can cope with anything you demand"). Companies were selected so as to cover all three supply chains, at each tier, and to take in varying firm sizes and capabilities. This continued until recurring themes emerged, triangulation was achieved and a point of theoretical saturation was arguably reached (Glaser and Strauss, 1967). A total of 16 firms from this network were studied (see Table I, which uses pseudonyms, reflecting their core function). Figure 1 shows the network in simplified form; it is of course, part of a much larger network.

\section{Data collection and analysis}

Ultimately, 20 semi-structured face-to-face interviews with senior representatives were conducted. This began with interviews in several SMEs upstream in the network (e.g. Precision Engineering Ltd). These companies were typically part of several supply chains and facilitated access to the wider network. The interviews were structured around themes taken from the supply chain flexibility literature including:

- collaborative relationships;

- information sharing;

- re-configuring the supply chain and changing sources of supply;

- the role of technology and inter-firm information systems;

- initiatives to reduce lead-times across the supply chain; and

- the positioning of inventory in the supply chain.

The main methods of data collection were single- and multiple-respondent face-to-face semi-structured interviews, plant visits/factory tours, observations, and secondary data from articles and web sites.

Borch and Arthur (1995) explain that: "analysing case study evidence is especially difficult because the connection between the data collection and the data analysis phase is not sequential, but interactive". That was true here: much more was known about the network when the last interview was conducted than when the first interview was conducted. Initial interviews had to focus on dyadic or triadic relationships with customers and suppliers or general questions about the network as a whole. Towards the end, it was possible to ask respondents more in-depth questions about the wider network.

Several measures have been taken to ensure the validity and reliability of the data analysis and interpretation process (Yin, 2003). Interview notes have been transcribed, analysed and condensed to ease comparability. On some occasions, details have been confirmed by respondents after the interview (e.g. through a follow-up

\section{Supply chain flexibility}

951 
IJOPM
29,9

952

Table I.

Overview of manufacturing companies interviewed

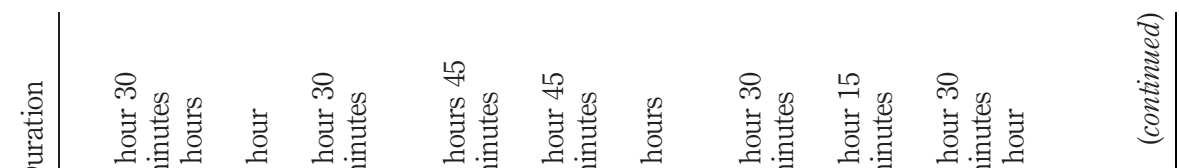

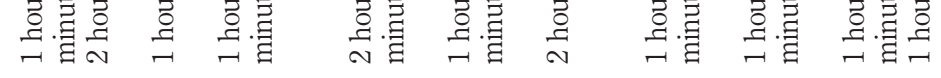

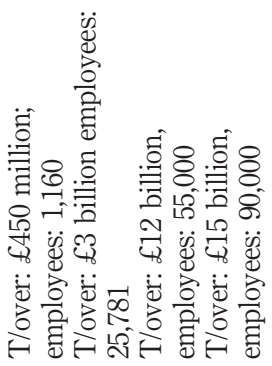

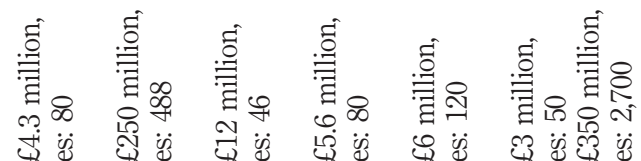

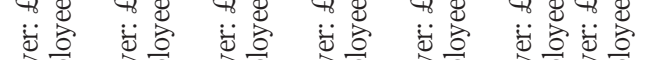

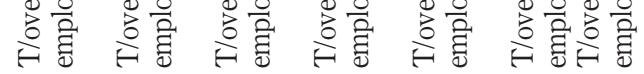

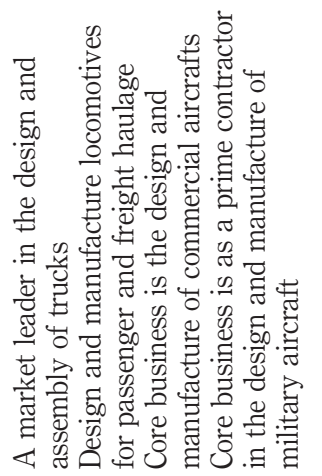

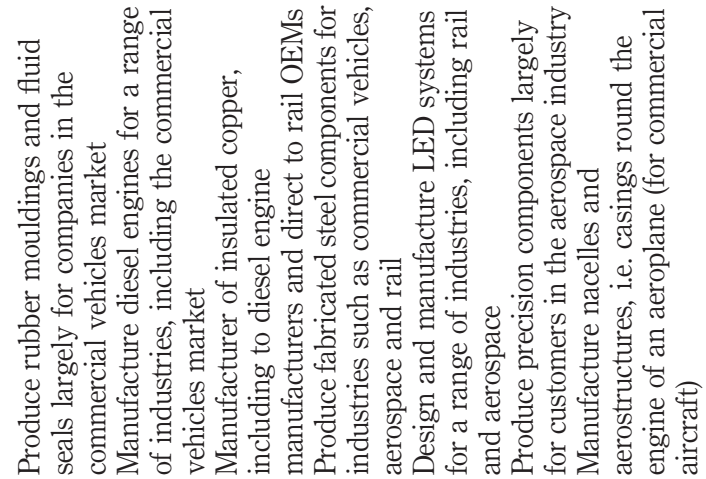

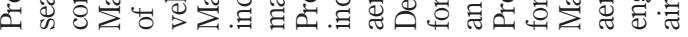

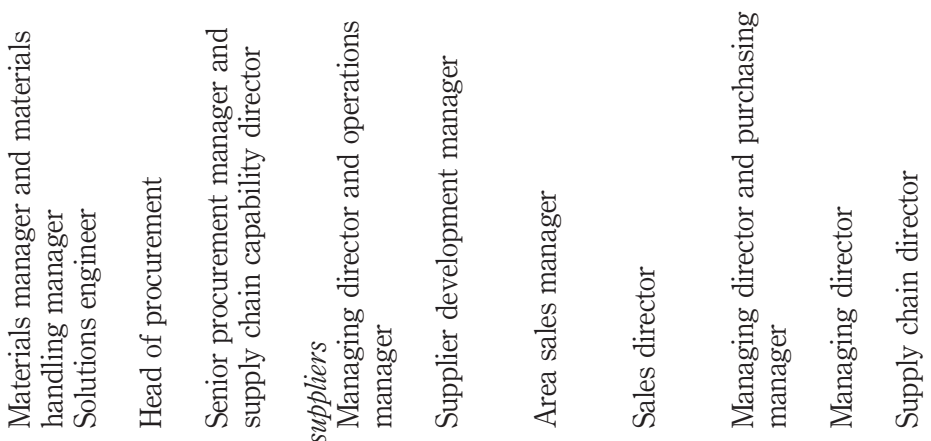

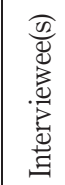

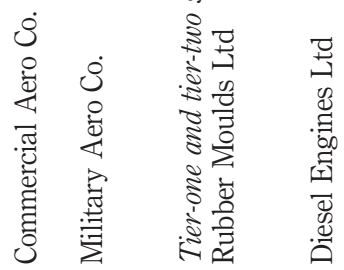

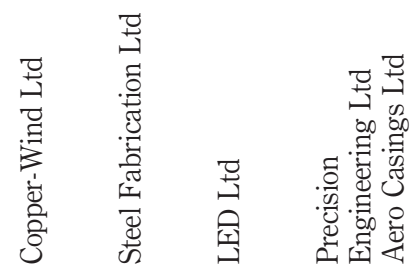




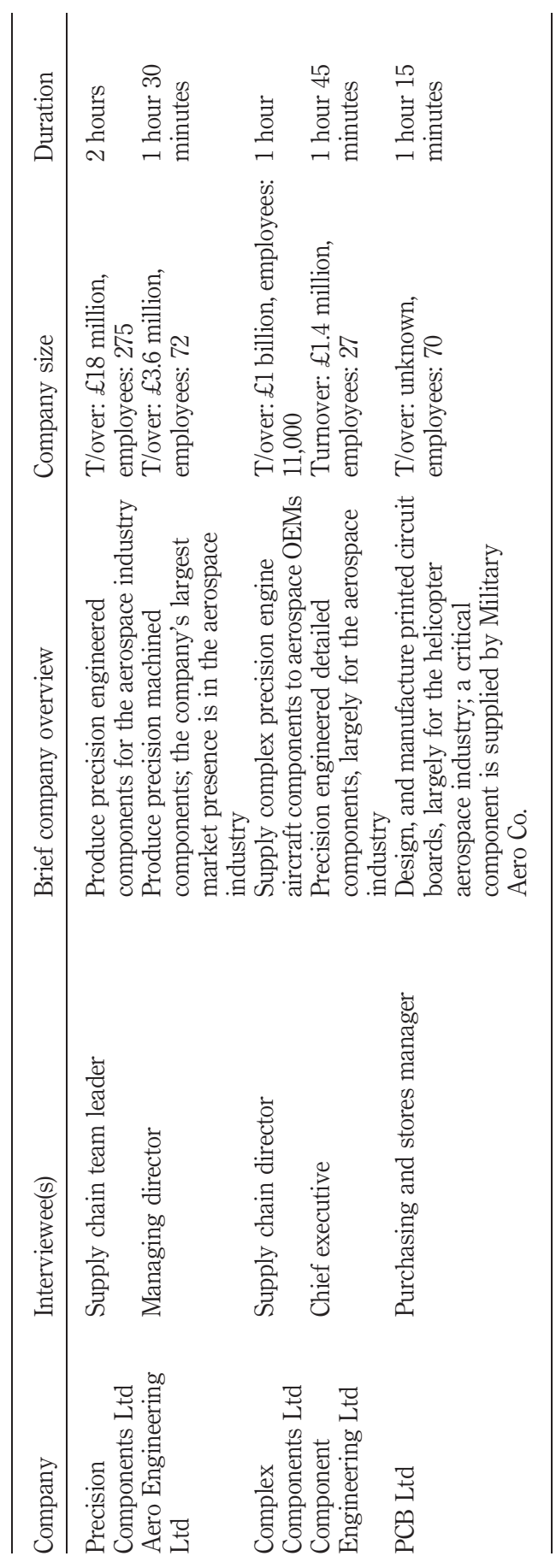

Supply chain flexibility

953

Table I. 
IJOPM

29,9

\section{4}

Figure 1.

Network of manufacturing companies studied

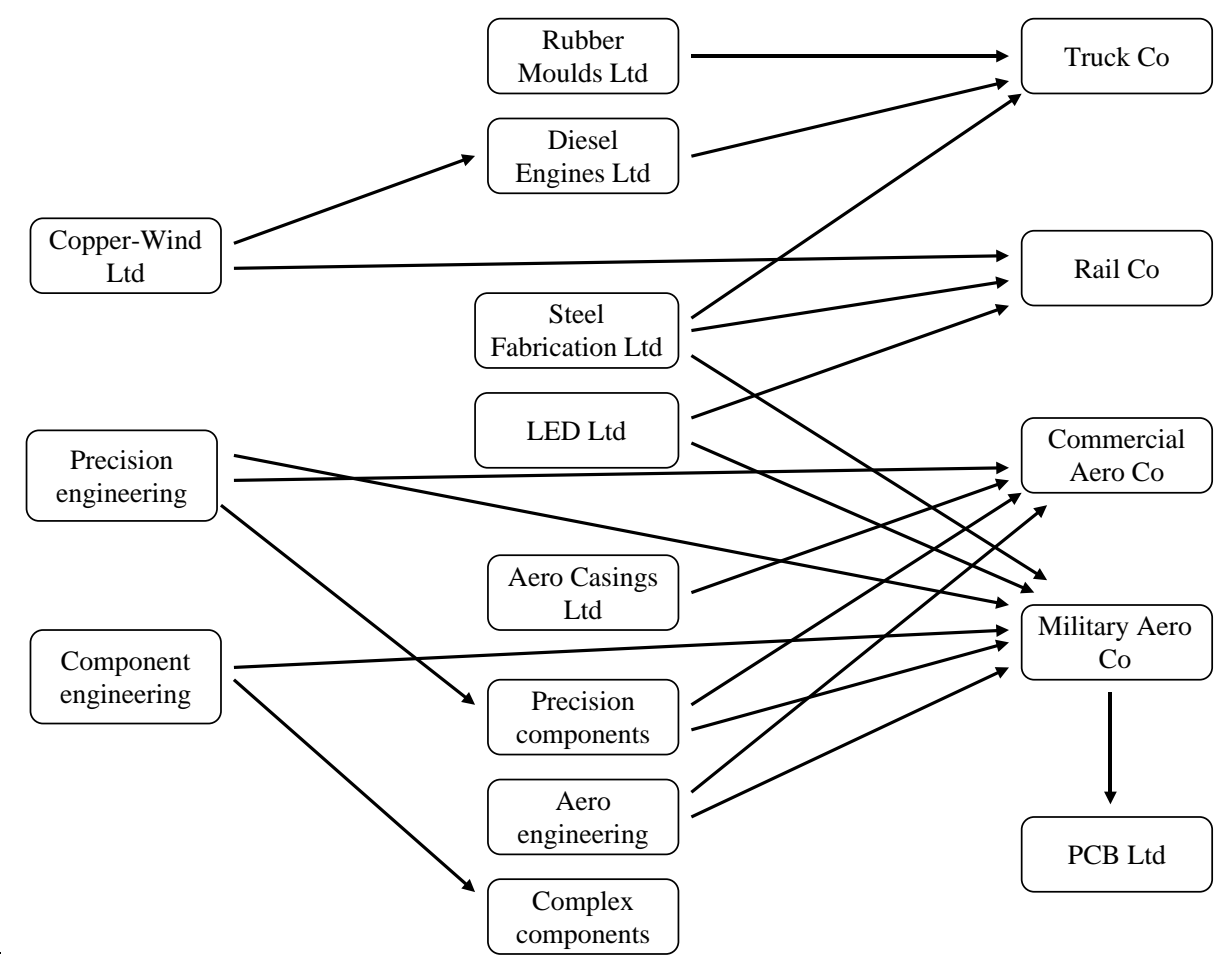

telephone conversation). Multiple researchers have been involved in the project but have explored the interview data independently. Important themes from the literature, our own collective ideas and recurring themes in the data have been used to cross-reference, categorise and sub-categorise extracts. Key quotations from the interviews have also been abstracted, compared and clustered. The analysis has looked for commonalities, shared experiences and distinctive differences between, for example, different tiers of the network. Triangulation has been sought both within firms (e.g. by comparing primary and secondary data) and between firms (e.g. by comparing the responses of inter-related companies). Moreover, since inter-related firms have been studied, triangulation is built into the research design. Process maps, tables and network diagrams have also been useful analytical tools. The manual analysis of transcripts has been complemented by use of a qualitative research software package (Atlas-t $i \odot$ ).

\section{Research findings: aspects of inter-firm flexibility}

The following subsections outline the findings of this study, organised around ten themes both taken from the literature and emerging as important from the data analysis. A summary of key findings is also presented in Table II.

Flexibility through collaboration and integration of the supply chain

The extent of collaboration and integration is important in determining the flexibility of the existing structure and the ease with which the supply chain can be re-configured. 
Aspects of flexibility

Collaboration and integration of the supply chain Increasing inter-firm collaboration and (e.g. building personal relationships; training and lead time reductions with rationalised supplier base)

Product design (e.g. supplier involvement in design; modularity and postponement)

Supplier qualification and training (e.g. traceability, quality initiatives, single/multisourcing and location)

Information sharing in the supply chain (e.g. customer demand information and supplier capacity availability)

Sourcing policies (e.g. free-issue materials, grouplevel procurement and third-party procurement)

Shared resources (e.g. group-level resource redistribution and horizontal collaboration)

Key points from the empirical evidence

integration can lead to a greater willingness by suppliers to cope with change

Investing in suppliers (e.g. training initiatives) can increase the speed at which the supply chain can respond to change

Limiting the extent of relationships with suppliers can increase the ease with which the supply chain can be re-configured

Involving suppliers in product design can increase supply chain flexibility in terms of more modular products

Postponement increases a supplier's ability to cope with specification change and allows customers to delay detailed ordering Supplier involvement in product design can increase supply chain reliance and reduce the ability to re-configure the chain

Acquiring local suppliers can facilitate JIT delivery and increase the chain's ability to respond to rapid change Industry characteristics affect the ability to rapidly change the supply chain design (e.g. supplier approval processes)

Sharing information (e.g. a supplier's available capacity) can improve ordering decisions and supply chain efficiency

A lack of information sharing creates uncertainty which affects investments in flexible resources at the firm-level

e-Business can provide a firm with means of rapidly entering and withdrawing from new markets

Large downstream supply chain members, with the most power and leverage, may co-ordinate procurement

Firm and inter-firm flexibility is affected by wider issues (e.g. the availability and price of raw materials)

Firms which are part of a larger enterprise can redistribute resources across plants in response to changes in demand

Information systems, such as enterprise software, can play a key role in organising the distribution of resources across plants

Horizontal collaboration (e.g. between SMEs) can provide short-term expansion (e.g. to increase range and volume)

Holding inventory (e.g. JIT delivery to customers Low inventory holding increases a customer's and strategic supply chain stocks)

\section{Supply chain flexibility}

955 specifications at the firm-level

Table II. Summary of aspects of inter-firm flexibility and empirical evidence 
IJOPM

29,9

\section{6}

Tactical outsourcing to purchase flexibility (e.g. subcontract manufacturing)

Leasing and hiring (e.g. flexible upstream firms and temporary capital equipment)

Standardisation and codification (e.g. supplier approval processes and design)
Key points from the empirical evidence

Low inventory holding by the customer (e.g. JIT delivery arrivals) implies more inventories and less agility "elsewhere"

High inventory holding in some (fast moving) contexts leaves a firm vulnerable to changes at other points of the supply chain

In other contexts (e.g. the market for replacement parts) inventory holding is key to responding to urgent unforeseen demand

Many upstream firms compete as subcontractors based on flexibility - "being able to do anything" for other firms in the chain

To be robust and "avoid" re-configuration, the supply chain is likely to contain some flexible firms that can absorb change

Many downstream firms are relatively rigid and outsource change to other supply chain entities with surge capacity

If change is considered short term, downstream firms may maintain stability by using upstream entities

Like upstream manufacturers, services (e.g. recruitment agencies) provide flexibility for other firms in the supply chain

Industry technological characteristics can inhibit the ability to cope with change through reconfiguring the supply chain Information systems using standard protocols reduce re-configuration difficulties

Upstream firms which are flexible may diversify to reduce reliance on particular industries or customers

Table II.

Close relationships provide one dimension of flexibility (e.g. a greater willingness on the part of the supplier to cope with change); on the other hand, such relationships can make supply chain re-configuration more difficult. As we will see, this is a pervasive theme of the whole analysis.

Many downstream firms had rationalised their supply base to a smaller number of preferred suppliers with whom closer relationships might be built. But this typically involves trade-offs with risk and flexibility in the supply chain. For example, Precision Components Ltd had reduced their number of suppliers but guard against over-reliance by ensuring that no supplier dedicates more than 10-15 per cent of its capacity to them. Many downstream firms have also initiated training, problem-solving and supply chain improvement programs with preferred suppliers, realising that, to have a greater impact on performance, it is important to look beyond the boundaries of the firm. The Supplier Development Manager of Diesel Engines Ltd explained that: 
[...] if we made internal lead-time savings of $20 \%$, the customer probably wouldn't even notice [...] but if this happens across the supply chain then they would start to see a difference.

Improvements such as cost savings made by suppliers are then shared with customers. It has been argued that for a supply chain to develop a successful and sustainable flexibility strategy, flexibility must provide benefits at each tier. Personal and social relationships between individuals in firms affect the level of service a customer gets from a supplier. The Managing Director of Aero Engineering Ltd, for example, stated that: "Personal relationships (with customers) are important [...] certain customers know they can 'lean' on us to get rush orders through the factory."

Many of the downstream companies have initiated lead-time improvement programs with suppliers. Although firms at the upstream end may be flexible, they are in less of a position to influence the total lead-time or speed of the supply chain and, as many are SMEs, may not have the personnel to dedicate to lead-time improvement programs. The Supply Chain Team Leader of Precision Components Ltd explained that: "managers in our smaller suppliers are already wearing several hats, so it can take time to get lead-time improvement measures in place". This suggests that the relative importance of flexibility and responsiveness varies with supply chain position.

Despite the above benefits, increasing integration makes it more difficult to re-configure the supply chain; Das et al. (2006) explain: "by fostering interdependencies, integration potentially creates inflexibility and impedes adaptation to uncertainty". This implies that supply chain flexibility is multi-dimensional; increasing the flexibility of the supply chain in one dimension can reduce the flexibility of the chain in another.

\section{Flexibility through product design}

Involving customers and suppliers in product design can improve flexibility. One way this happens is early supplier involvement, which can reduce development time, product complexity and costs while improving ease of manufacture and quality. The Sales Director of Steel Fabrication Ltd explained that:

[...] $80 \%$ of our work is build-to-print, so by the time we get to the production stage the designs are "set in stone" (fixed). Through greater collaboration at the design stage, we try to make sure that the design suits our manufacturing capabilities, makes the best use of the latest technology that we have to offer, and makes the best use of materials (i.e. standard materials with short lead-times).

Another way to improve flexibility is through the use of modular product designs, which can enable the supply chain to produce product variations quickly and allow re-manufacturing. Postponement strategies and increasing parts commonality can also enhance flexibility. For example, Rail Co. maintains flexibility by keeping materials in standard forms, which can be used on many different jobs, for as long as possible. Diesel Engines Ltd share component lead-time information with their customers and encourage them to select modules with similar lead-times; customers can then trade-off product choice against lead-times (Spring and Sweeting, 2002). Such product design decisions are closely linked to supply chain design (e.g. the positioning of the customer order de-coupling point).

While involving suppliers can improve the design of products and processes, of course, there is a risk that deeper inter-firm ties may be exploited to reduce

\section{Supply chain flexibility}


IJOPM

29,9

\section{8}

re-configuration flexibility. The Area Sales Manager of Copper-Wind Ltd, for example, explained that:

[...] we get involved in product improvement and problem solving initiatives with the customer, but if we improve a process we don't show the customer how we've done it so they can't take the business away and give it to someone else.

\section{Flexibility through supplier qualification and training}

The characteristics of an industry and design of the supply chain affect inter-firm flexibility. In the aerospace sector, large downstream companies have externalised much of the manufacturing process but rarely re-configure the supply chain in a significant way. The need for traceability and to use approved suppliers means that Commercial Aero Co., for example, dictates which tier-two suppliers their tier-one suppliers can use. Traceability creates administrative ties between companies and restricts a supplier's ability to change sources of supply. This is also true, to an extent, in the commercial vehicle supply chain. The Area Sales Manager of Copper-Wind Ltd explained that: "in terms of choosing suppliers of copper and enamel - we are totally inflexible on both - we buy them from who we are told to".

Supply chain improvement programmes extend control and influence upstream, enhancing flexibility in some respects, reducing it in others. These effects can be direct or indirect. Diesel Engines Ltd, for example, had hoped that the training of their tier-one suppliers would cascade to tier two; however, this has not happened, so they are now training some tier-two suppliers directly. Similarly, Rail Co. avoid getting involved in the wider supply chain unless tier-one suppliers are unable to gain sufficient leverage with their suppliers. Other aspects of supply chain design include the location of suppliers (e.g. local versus global suppliers). Truck Co. uses many local suppliers, developing close relationships, JIT deliveries and ready availability of supplier staff to help resolve technical problems. Clearly, there are different strategies to designing, managing and co-ordinating the supply chain; flexibility may be evident in each but presents itself in different forms.

\section{Flexibility through information sharing in the supply chain}

Improving real-time information-sharing between firms can help to improve flexibility by giving firms greater visibility and time to respond to change. However, our interviews suggest that this is not so widespread in practice, with consequences for levels of trust - and hence flexibility - between firms. The Managing Director of Rubber Moulds Ltd commented that:

$[\ldots]$ at the moment, we find information sharing to be like playing tennis against an open court - nothing comes back! [...] After a while you start to wonder what's going on at the other end that you don't know about.

Some suppliers are unwilling to develop their own manufacturing flexibilities by investing in specialist machinery or materials to meet a particular customer's requirements, because of a lack of information-sharing about long-term demand. The Managing Director of Aero Engineering Ltd, for example, commented that: 
[...] the lack of transparency and trust in our aerospace supply chains creates uncertainty, which stops us making capital investments, which in turn limits our ability to be flexible, responsive and to drive down costs.

This demonstrates the interplay between flexibility at the firm level and issues in the wider supply chain.

It is also valuable for suppliers to provide customers with information about constraints such as bottleneck work centres and the current shop load. The Supply Chain Director of Complex Components Ltd explained that:

[...] it is important that we understand both the constraints and the capabilities of our suppliers and that we work out what we need to do to get the best service from our supply chain.

This can improve supply chain flexibility, as work can be allocated to suppliers with the potential to react quickly. But evidently this is not a widespread practice. e-Business - a related but more widespread use of the internet - also provides flexibility; for example, by having a web-presence, LED Ltd can quickly move into new markets and "withdraw" at less cost. The Purchasing Manager of LED Ltd explained that:

[...] our recently launched web-store gives us a global reach without having to commit to a physical presence in a particular country. Customers can go online, view our current inventory levels and order products at the click of a button.

\section{Flexibility through sourcing policies}

In reducing the number of suppliers, original equipment manufacturers (OEMs) have also shifted the responsibility for many procurement activities upstream to tier- and tier-two suppliers. These are often smaller companies with less purchasing leverage and so may have to accept large minimum order quantities, higher prices or longer lead-times from their suppliers. If volumes increase, this reduces the ability of the firm to "change what they do"; if prices increase, this can have knock-on effects for costs throughout the supply chain; and, if lead-times increase, the ability to respond quickly will reduce. The tier- and tier-two companies interviewed have adopted various strategies for gaining the leverage that they need in order to negotiate competitive prices and lead-times with material providers without an increase in order size. Three notable inter-firm strategies were used in the firms studied. Particularly in the aerospace sector, "free-issue" arrangements are widely used. These involve materials being bought by the end customer, usually the OEM, then issued to the supplier to work on. The supplier never assumes ownership of the material, but is simply paid for the added-value work they do on it. The Managing Director of Component Engineering Ltd explained that: "companies higher up in the supply chain tend to have more 'clout' (power) when it comes to purchasing". Therefore, the company has persuaded the customer to take back procurement responsibility and provide them with "free-issue" materials to reduce costs. But other customers interviewed are reluctant to purchase materials for their suppliers, as part of the original motivation for outsourcing was to reduce purchasing administration. Complex Components Ltd have found a compromise for their suppliers, by negotiating an agreement with raw material suppliers so that any of Complex Component Ltd's suppliers can order raw materials directly at the same price that Complex Components Ltd would be able to obtain.

\section{Supply chain flexibility}


IJOPM

29,9

960
A second strategy is consortium purchasing among several independent firms, or the use of centralised procurement among firms in the same group. By purchasing together, SMEs and other low-volume producers are able to gain greater economies of scale than they would be able to individually. Similarly, companies such as Copper-Wind Ltd, that are part of a wider enterprise, are able to purchase standard materials at a lower cost by doing so at the group level.

Many of the companies negotiate contracts for fixed prices and quantities over an extended period of time, effectively forecasting future material purchases; for standard materials and common parts, this can be a relatively low-risk strategy. This also reflects uncertainty regarding the price and availability of raw materials, particularly metals. The Supply Chain Capability Director of Military Aero Co explained that:

[...] we tend to buy the titanium we need in advance (in "standard form") on a fixed price contract (e.g., for a two-year period). This allows us to cope with the volatility of material supply and maintain flexibility [...] we will always need titanium.

As with the other sourcing strategies, the impact of this on flexibility is not straightforward: there is usually a long-term and/or greater commitment to a particular supplier - which might be seen to reduce flexibility - but an anticipated increased responsiveness as a result of the increased importance of the customer to the supplier's business.

\section{Flexibility through shared resources}

Firms that are part of a larger enterprise are able to take advantage of extra sources of flexibility that are not available to independent companies. In addition to procurement, this can take the form of risk pooling, by aggregating and re-distributing resources from an under-loaded to an over-loaded site to cope with demand fluctuations across the group. The Supply Chain Team Leader of Precision Components Ltd stated that:

[...] there is more and more collaboration starting to happen within the group - quite often we have the plant and they (another group member) have the personnel, one way or another the job gets done between us.

Information technology, including enterprise systems, can play an important role in facilitating this inter-plant flexibility: for example, Copper-Wind Co.'s group uses web technology to provide inventory visibility between plants. If inventory is not allocated to a customer, it can be transferred to another plant within the group.

Independent firms are able to replicate some of the above by forming strategic alliances within industry clusters. Volume flexibility can also be developed by collaborating with sometime-rival companies to form temporary networks. Precision Engineering Ltd, for example, has begun to bid jointly with competitors for contracts it cannot deliver alone. The Managing Director stated that:

[... . normally we wouldn't have the capacity to do this job, but by submitting a joint tender with another company that we are used to competing against, we know that between us we can.

By developing a horizontal alliance they can pool risk and create a "temporary organisation" with more leverage and capability. In this instance, proximity facilitates this, in keeping with the findings of Bell (2005). Clearly, some of the above ways in which flexibility manifests itself in an inter-firm context cannot be directly replicated at the intra-firm level. 
Flexibility through holding inventory

When designs change very frequently, low inventory holding is an important way to avoid obsolescence, which can result in scrap and rework. Such changes are a major challenge and further enforce the importance of information sharing and working with suppliers on product design. Interviewees noted that, to maintain flexibility, it is important that design changes are communicated rapidly through the supply chain. The Materials Handling Manager of Truck Co., for example, commented that:

[...] to be flexible and responsive, it is important to communicate [...] as soon as we know that changes are coming, we need to start talking to other people in the supply chain [...] when we get a new order, our most important suppliers will be informed within twenty-four hours.

While these and other advantages of lean principles are well known (Womack and Jones, 2005), inventory plays an important role in many flexible supply chains. In the aerospace and rail aftermarkets, for example, demand for spares is unpredictable and so inventory is needed to maintain customer service. The Supply Chain Director of Complex Components Ltd explained that:

[... . we do a lot of repair work; if a customer comes to me and orders three parts that they last ordered six years ago, they are ordering them because they need them urgently. It's important that we have these on hand [...] yes, we can adopt lean principles in areas of our business but only where they don't compromise our customer service levels.

The positioning of inventory also affects where the costs and risks are absorbed. There is evidence here of "risk passing" to the supply-side and/or to the less powerful firms. While this provides advantages for the customer, there are considerable drawbacks for the flexibility of the supplier. The Senior Procurement Manager of Military Aero Co explained the severity of this and the effect of wider "environmental" factors and company size:

[...] political decisions may delay the start of production by months (or indefinitely) and this has an impact throughout the supply chain. A tier-three member of the supply chain that has invested in forward inventory could end up shutting down.

Suppliers to Diesel Engines Ltd do not receive payment until their goods are used, but are expected to hold two months' inventory so that Diesel Engines Ltd is protected against any disruptions and can change sources of supply seamlessly.

To conclude the discussion above, although some authors have argued that we are now in an era of supply chains competing against supply chains (Croom et al., 2000) in which flexibility can be a key competitive "weapon" - the focus in much of the above is on what inventory decisions are best for the firm rather than the supply chain.

\section{Flexibility through tactical outsourcing}

Outsourcing can allow a company to focus on their core competencies and also to reduce their own need to be flexible. Truck Co., for example, is a pure assembly (and design) plant. Semlinger (1993) explains that outsourcing is not only about economising on transactions but also about avoiding capital commitments and turning fixed costs into variable costs: "outsourcing offers considerable gains in flexibility and serves to reduce the risks of capacity utilisation and amortisation, especially when demand is uncertain, irregular, low and/or temporary".

\section{Supply chain flexibility}


IJOPM

29,9

962
Our interviews suggest that upstream firms seek competitive advantage through being flexible and able to meet a wide range of customer requirements. These companies also have to be flexible because they typically have less notice of changes than their customers. Those at the downstream end are more rigid, having outsourced their "need to be flexible", and are more interested in improving supply chain throughput speed than in-house flexibility. Small subcontractors meet a wide range of customer requirements by investing in their own manufacturing flexibility, for example, by having flexible machines, a flexible work force and the ability to rapidly increase capacity. Component Engineering Ltd, for example, have many small, inexpensive machines that are rarely used, but are available should they be needed. LED Ltd has a large shop floor, part of which is rented out to other companies: if demand increases, they can expand into this space. Some downstream companies try to change the culture of their suppliers; for example, Commercial Aero Co. is attempting to persuade suppliers to operate at around 80 per cent utilisation, instead of 100 per cent, so that they have capacity available to surge at short notice. The Head of Procurement at Commercial Aero Co. explained that:

[...] we are working hard to change the culture of our suppliers. Instead of working at full capacity all the time, we want them to lower their utilisation so they have the ability to surge when we need them to. Flexibility for us has a lot to do with planning and being able to turn resources on and to turn them off.

Complex Components Ltd require raw material suppliers to supply steel pre-cut instead of supplying standard sheets that then have to be cut to size; this means that the materials may be unsuitable for other jobs but can result in shorter lead-times. The Supply Chain Director explained:

We have moved some of our raw material providers down the supply chain. Instead of providing us with standard sheet metal, they now supply us with pieces cut to length for specific jobs. This relies on a commitment to the order from our customer but allows us to hold less stock, reduces both costs and lead-times and frees up our laser machines (from simple 2D cutting jobs) for more complex 3D operations.

By having flexible suppliers, these companies can maintain their confidence to accept jobs - if they cannot do the work, one of their suppliers will be able to. The Supply Chain Team Leader of Precision Components Ltd explained:

[... . we don't turn work away - if we don't have the capability to do the job, the chances are that one of our suppliers will have, and we can then outsource the work to them.

The use of outsourcing also provides a firm with access to skills not available internally. The Managing Director of Component Engineering Ltd commented that:

[...] our tier-one customers have nowhere near the machining capabilities that we have [...] flexibility (and innovation) is what wins us our business - it is a deliberate ploy on our part.

\section{Flexibility through leasing and hiring}

Several interviewees highlighted the role of services, such as plant-hire firms and recruitment agencies, in providing flexibility. This provides, for example:

- the ability to adopt a level-capacity plan and then supplement internal capacity to fulfil peaks; 
- improved responsiveness to change;

- continuity (e.g. during machine breakdowns or staff absence); and

- flexible access to resources only required in the short-term.

Using temporary recruitment and plant-hire also allows a firm to manage risk; if the change in demand is later found to be a longer-term change, the company may then decide to recruit a permanent member of staff or purchase a piece of machinery The Solutions Engineer of Rail Co. explained that:

[...] when we first started to re-bar motors, we had only one small order and the equipment we needed cost $£ 50,000$, so we hired the machines. Then in time we got a contract to re-bar a fleet of motors [...] at this point we invested in the kit (equipment) ourselves.

From the above, it follows that risk and the longevity of change affect the approach taken to creating flexibility. Where there is high risk or a short time horizon, companies often use external resources that can be quickly "turned on and off".

Transportation flexibility is also important. Rubber Moulds Ltd, for example, use haulage firms to deliver small volume jobs to costly remote locations, leaving their own fleet to deliver full loads to more convenient locations. It follows that manufacturing and service operations both have important roles to play in creating supply chain flexibility.

\section{Improving flexibility through standardisation and codification}

The ability to re-configure the supply chain is an important dimension of flexibility; however, lengthy supplier approval processes, tacit knowledge of production procedures and the misalignment of information technology between customers and suppliers, can create significant barriers to re-configuration. As already discussed, in the aerospace industry, the ability to switch sources of supply in the short-term is limited by the supplier approval process and the need for complete traceability. This hinders re-configuration and can lead to building stable long-term collaborative relationships out of necessity. The Supply Chain Capability Director of Military Aero Co. explained that: "it is very rare for us to switch from sourcing something from one supplier to sourcing it from another [...] there would have to be something seriously wrong".

The mutual experience that long-term partners possess is important in all three industries in our network. Partly, this is because of the relatively complex nature of the products - new suppliers often have to go through steep technological learning curves. There also often arises the need for informal adaptations when changes to product and process designs are not documented in a timely manner, and these are best carried out in established relationships. On some occasions, supply chain actors deliberately attempt to create dependencies which make them less vulnerable and which further restrict the flexibility of customers to change sources of supply.

For many SMEs in the aerospace industry, flexibility is now a deliberate strategy. Large organisations often outsource work to upstream SMEs at the "last minute", demanding short lead-times; coping with these orders requires flexibility. Many SMEs have reduced their specialisation and diversified into other markets to mitigate the effect of future changes in the sector, a practice that is particularly important for SMEs, lacking as they do the financial resources to absorb market volatility. The Managing Director of Aero Engineering Ltd, for example, stated that: 
IJOPM

29,9

964 $[\ldots]$ having a presence in four markets at once makes us less vulnerable to change $[\ldots]$ we just have to hope that they don't all "go under" at the same time.

Such diversification has, however, arguably reduced the flexibility of the aerospace supply chain; interviews suggest that companies which diversified during the last downturn have not returned to the industry with the same level of available capacity.

A number of initiatives are being undertaken to remove barriers to integrating new suppliers. These include the standardisation of supplier approval processes across the big aerospace companies so that once a supplier is approved for one customer, it is approved for all, and the implementation of new procedures designed to improve knowledge management. Information technology barriers to supplier integration are also reducing; web-enabled electronic data interchange (EDI) systems, for example, are more flexible and easier to align across different supplier systems than "traditional EDI" systems. While, at present, many of the companies interviewed send and receive information using emails and spreadsheets (available to most companies), more sophisticated, web-enabled, customer-supplier interfaces may become a prerequisite to working with some companies in the future.

\section{Discussion of findings}

The literature review highlighted the need to study networks in order to better understand and investigate flexibility in an inter-firm context. Building on this, we examined the flexibility of a network of 16 manufacturing companies and asked:

$R Q$. What specific inter-firm practices are used to achieve increased flexibility in buyer-supplier pairs and in the wider supply chain or network, and how do these practices and effects interact?

The previous section has drawn out a number of themes in the practices identified, in the rationale for their adoption, and in their effects and interactions. This section aggregates these further and develops a typology of inter-firm flexibility patterns.

\section{Configuration flexibility versus planning and control flexibility}

First of all, it is clear from the data that downstream firms seek to improve the flexibility of the chain as a whole by using external sources, both through systematic outsourcing and more ad hoc sub-contracting and use of plant-hire firms and temporary labour. Clearly, there are reasons for outsourcing other than a quest for flexibility. Nevertheless, in the sectors we studied, which are all characterised by high end-product variety and shifting aggregate demand levels, downstream firms benefit from concentrating on a relatively short span of activity - often limited to development, design, and final assembly - and allowing their supply network to accommodate much of the change. Part of the logic here is that these typically more diversified and less capital-intensive upstream firms can offset volatility in demand in one sector or customer against relative stability in another: in other words, they pool risk (Eppen, 1979). The downstream firms, however, do not externalise their difficulties and then, as it were, wash their hands of them. In various ways and for various reasons, there are still "umbilical cords" of commitment and dependency between successive tiers in the network. Supplier qualification and traceability requirements, especially in aerospace, make it difficult to change suppliers and so, for better or worse, supply relationships are very enduring. Furthermore, customers see benefit in 
reducing their ability to change suppliers - what we might term configuration flexibility - in the interest of other forms of flexibility such as volume changes, schedule changes and design changes - what we might term planning and control flexibility. Commitment to relationships is developed through various practices: developing personal relationships, using local suppliers, mutual adaptation of information systems, collaborative design and so on. Some of these practices are engaged in more willingly than others, by both buyers and suppliers, as discussed above. Perceptions of flexibility are also very important here: for example, a second-tier supplier "told" by their customer which raw material supplier to use might feel regret at a perceived loss of autonomy and independence, or might feel better able to "call the shots" with the supplier, given the extra influence of the downstream customer. The motivation for the downstream customer is usually some combination of a desire for cost reduction and improved planning and control flexibility for the supply chain as a whole. Has the second-tier supplier increased its flexibility? Does it matter? Overall, it seems that the supply chain achieves improved planning and control flexibility. Upstream firms seem to fit the pattern identified by Lyons and Bailey (1993): that is, they maintain configuration flexibility, i.e. ability to serve several customers or sectors, partly out of a deliberate strategy to spread risk, partly because they do not feel they have the commitment they would like from their customers and which would otherwise encourage them to make more specialised investments.

\section{The interplay of configuration flexibility with planning and control flexibility}

The over-arching insight of this study is that there is a complex interplay between configuration flexibility and planning and control flexibility in supply chains. Furthermore, this exists at vertical dyadic, horizontal dyadic, triadic and chain levels of analysis. This section will draw out some of the more general implications of these findings. Although we have not extended our data collection to determine any absolute measures of supply chain performance, but rather to explore the perceived efficacy of various practices in achieving various forms of flexibility, it seems that these practices are adopted in order to achieve desirable performance outcomes. Flexibility is rarely, if ever, an end in itself, but a means of achieving on-time and/or fast delivery of the right quality of product or service with appropriate costs. Flexibility - either demonstrated in the past or imputed by evaluating capabilities and capacities - may be the reason for a supplier being chosen, but it is the availability of the product or service that the customer pays for, not the flexibility per se. Either of these two types of flexibility may, then, lead to improved supply chain performance, in terms of quality (specification and conformance), speed, dependability and cost.

Our data suggest that certain practices contribute to or detract from each form of supply chain flexibility, i.e. configuration flexibility and planning and control flexibility. While many of these practices are likely, each in their own right and in their own way, to influence supply chain performance, we suggest that it is useful also to capture their effects in the two meso-level supply chain flexibility constructs we have identified, which in various ways tend to militate against one another. These relationships can be shown in diagrammatic form in Figure 2, which is intended to provide a basis for more systematic testing of the insights drawn from our data. Figure 2 shows the practices that emerge from our analysis, the two types of supply chain flexibility - configuration and planning and control flexibilities - and supply chain performance. We do not have

\section{Supply chain flexibility}

965 


\section{IJOPM}

29,9

\section{6}

\section{Figure 2.}

A proposed model of supply chain flexibility

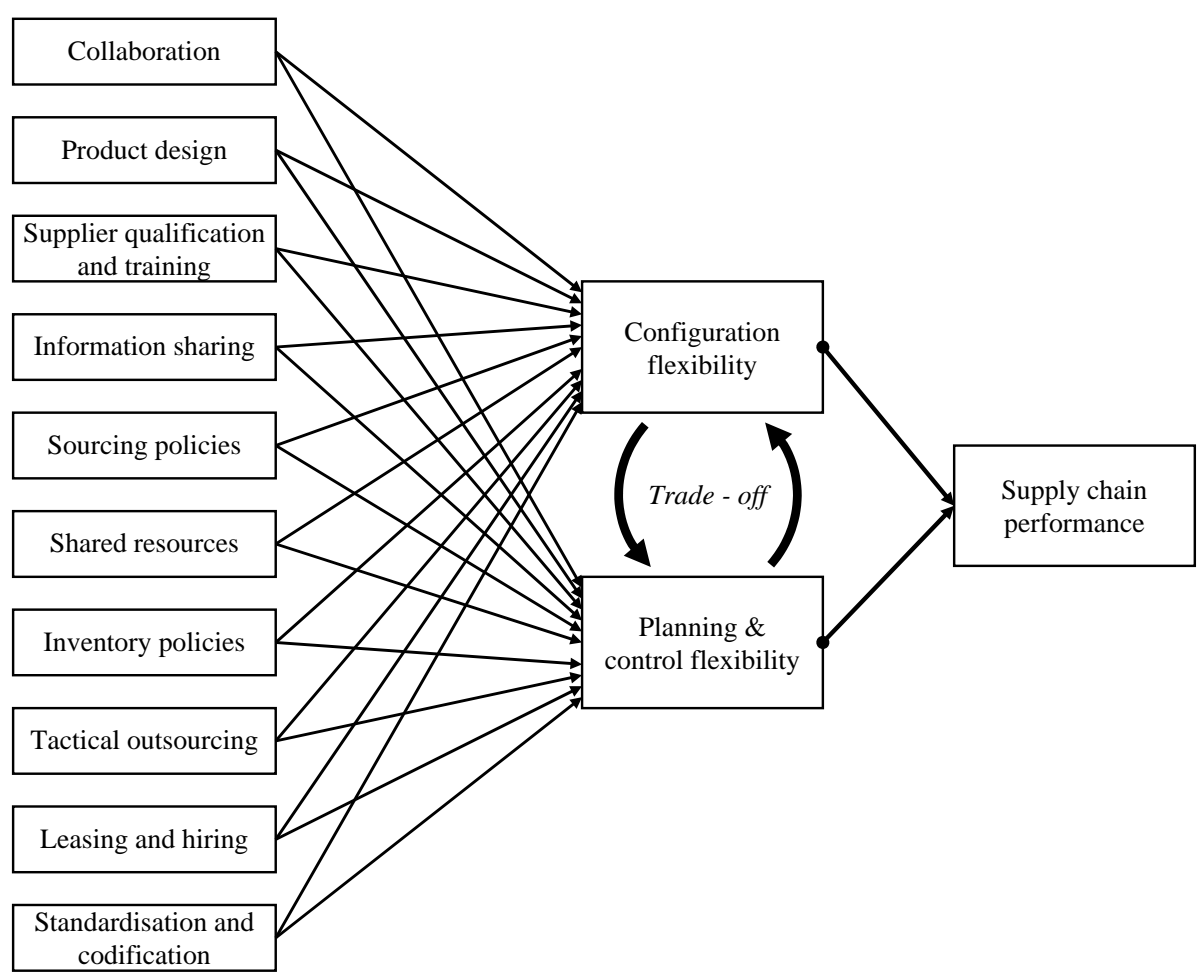

sufficiently fine-grained or extensive data fully to specify the direction of the effect of each of the practices we have identified on each form of supply chain flexibility: that would be the task of future research to test the model. The practices are indicated according to the ten areas into which we have grouped our findings in the sections above. While these suggest themselves to us from our analysis, there are other possible groupings: again, it would be the aim of future research to refine and perhaps consolidate these. Also, if the intention were to attempt to measure them, some would need to be expressed in terms suited to that next step, e.g. "product design" would need to be reduced to parameters that might be measured, e.g. "extent of use of modular design".

All that said, two conjectures arise from this analysis. First, it seems that, taken together, certain sets of practices mutually reinforce one another to provide one or other of the flexibility types. These are, we suggest, more than the sum of their parts in their effect, i.e. firms aiming to achieve, say, configuration flexibility may need to adopt all practices positively related to it, rather than "cherry-picking" only a few of them. (A similar argument has been made in respect of JIT purchasing practices (Gonzalez-Benito and Spring, 2000; Gonzalez-Benito et al., 2000)). Second, it follows from this that there is a trade-off between the two flexibility types, and managers make more or less deliberate choices to emphasise one or the other. If we accept this argument, another question arises: on what basis do managers choose which form of supply chain flexibility to emphasise, and why? For example, is configuration flexibility more important during product/service design and development, and planning and control 
flexibility more important during later stages of the product life cycle? This may have serious implications for supply management policies in any firm, but particularly in firms with multiple offerings at different stages of maturity. In these latter firms and their networks, there would be a need for both types of flexibility to co-exist - arguably an instance of what Tushman and O'Reilly (2002) call the "ambidextrous organisation".

Speculating slightly further beyond the data, we suggest that managers not only position their flexibility according to circumstances, but also work to reduce the extent to which improving on one dimension detracts from performance on the other - what Da Silveira and Slack (2001) would term trade-off "sensitivity".

\section{Conclusions and implications Contribution}

This study is among the first to examine flexibility in a network of inter-connected supply chains. As such, it adds in a number of ways to the understanding of the inter-organisational aspects of flexibility, their interaction with one another, and their interaction with forms of flexibility within the firm. Flexibility is strategically important to firms and to supply chains, and the study provides evidence of the ways in which organisations strike various balances between flexibility and stability. Outsourcing is certainly used to reduce the need for internal flexibility, but then commitment to inter-firm relationships is used to enhance flexibility in supply between firms. We delineate two major elements of flexibility in supply networks: configuration and planning and control flexibilities, and suggest that most of the phenomena observed are about firms finding mutually appropriate trade-offs between these elements with their direct and indirect network counterparts. It is certainly not the case that all firms in supply networks are, or should be, as flexible as possible along all dimensions of flexibility.

\section{Managerial relevance}

In the broadest sense, this study should make it clear why it is useful to take a network view when analysing supply network strategy from the perspective of procurement or, indeed, marketing. More specifically, the proposed flexibility types may offer a descriptive and prescriptive strategic "shorthand" for managers developing appropriate supply networks, and an understanding of the implicit and explicit trade-offs involved in their supply network decisions and practices.

\section{Limitations and suggestions for further work}

The study has benefitted from being carried out in inter-connected supply chains, but this means that the end products and some industry characteristics are rather similar across the whole network, i.e. very complex, high-value products and relatively long lead-times and product life-cycles. It would be useful, therefore, to extend the approach to study sectors such as grocery or fashion retailing, where lead-times and product life-cycles are much shorter and demand patterns are more volatile, and in service supply chains, where other mechanisms and practices may be involved. Future theory-building and development studies could also take a longitudinal perspective, collecting data on actual changes that take place in multi-firm networks. This could lead to the development of sharper constructs for the set of supply chain flexibility practices shown in Figure 2. Subsequently, a model in the form of Figure 2, but with

\section{Supply chain flexibility}

967 
IJOPM

29,9 more precisely specified practices and constructs, could be tested through large-scale empirical methods such as surveys. This would provide an alternative means to explore the two forms of supply chain flexibility - configuration and planning and control flexibilities - and the relationships between them.

\section{8}

\section{References}

Aprile, D., Garavelli, A.C. and Giannoccaro, I. (2005), "Operations planning and flexibility in a supply chain”, Production Planning \& Control, Vol. 16 No. 1, pp. 21-31.

Bartunek, J.M., Rynes, S.L. and Ireland, R.D. (2006), "What makes management research interesting and why does it matter?", Academy of Management Journal, Vol. 49, pp. 9-15.

Bell, G.G. (2005), “Clusters, networks and firm innovativeness”, Strategic Management Journal, Vol. 26, pp. 287-95.

Benbasat, I., Goldstein, D.K. and Mead, M. (1987), "The case research strategy in studies of information systems", MIS Quarterly, Vol. 11 No. 3, pp. 369-86.

Bertrand, J.W.M. (2003), "Supply chain design: flexibility considerations: Chapter 4 of Supply chain management design, coordination and operation", in de Kok, A.G. and Graves, S.C. (Eds), Design and Analysis of Supply Chains: Handbooks in Operations Research and Management Science, Vol. 11, Amsterdam, North Holland, pp. 133-98.

Borch, O.J. and Arthur, M.B. (1995), "Strategic networks among small firms: implications for strategy research methodology”, Journal of Management Studies, Vol. 32 No. 4, pp. 419-41.

Chang, S.-C., Yang, C.-L., Cheng, H.-C. and Sheu, C. (2003), "Manufacturing flexibility and business strategy: an empirical study of small and medium sized firms", International Journal of Production Economics, Vol. 83, pp. 13-26.

Croom, S., Romano, P. and Giannakis, M. (2000), "Supply chain management: an analytical framework for critical literature review", European Journal of Purchasing \& Supply Management, Vol. 6, pp. 67-83.

Das, A., Narasimhan, R. and Talluri, S. (2006), "Supplier integration - finding an optimal configuration", Journal of Operations Management, Vol. 24, pp. 563-82.

Da Silveira, G. and Slack, N. (2001), "Exploring the trade-off concept", International Journal of Operations \& Production Management, Vol. 21 No. 7, pp. 949-64.

de Toni, A.F. and Tonchia, S. (2005), "Definitions and linkages between operational and strategic flexibilities”, Omega, Vol. 33, pp. 525-40.

Duclos, L.K., Vokurka, R.J. and Lummus, R.R. (2003), "A conceptual model of supply chain management”, Industrial Management \& Data Systems, Vol. 103 Nos 5/6, pp. 446-56.

Eisenhardt, K.M. (1989), "Building theory from case study research", Academy of Management Review, Vol. 14 No. 4, pp. 532-50.

Eisenhardt, K.M. and Graebner, M.E. (2007), "Theory building from cases: opportunities and challenges", Academy of Management Journal, Vol. 50 No. 1, pp. 25-32.

Eloranta, E., Lehtonen, A. and Tanskanen, K. (1995), "Fast, flexible and cooperative supply chains - key issues for the survival of European industry", Production Planning \& Control, Vol. 6 No. 3, pp. 238-45.

Eppen, G. (1979), "Effects of centralization on expected costs in a multi-location newsvendor problem”, Management Science, Vol. 25, pp. 498-501.

Fisher, M. (1997), "What is the right supply chain for your product?", Harvard Business Review, March/April, pp. 105-16. 
Fisher, M., Hammond, J.H., Obermeyer, W.R. and Raman, A. (1994), "Making supply meet demand in an uncertain world", Harvard Business Review, May/June, pp. 83-93.

Fredericks, E. (2005), "Infusing flexibility into business-to-business firms: a contingency theory and resource-based view perspective and practical implications", Industrial Marketing Management, Vol. 34, pp. 555-65.

Fredriksson, P. and Gadde, L.-E. (2005), "Flexibility and rigidity in customization and build-to-order production”, Industrial Marketing Management, Vol. 34, pp. 695-705.

Garavelli, A.C. (2003), "Flexibility configurations for the supply chain management", International Journal of Production Economics, Vol. 85, pp. 141-53.

Gerwin, D. (1987), "An agenda for research on the flexibility of manufacturing processes", International Journal of Operations \& Production Management, Vol. 7 No. 1, pp. 38-49.

Gerwin, D. (1993), "Manufacturing flexibility: a strategic perspective”, Management Science, Vol. 39 No. 4, pp. 395-410.

Glaser, B.G. and Strauss, A.L. (1967), The Discovery of Grounded Theory: Strategies for Qualitative Research, Weidenfeld \& Nicholson, London.

Golden, W. and Powell, P. (1999), "Exploring inter-organisational systems and flexibility in Ireland: a case of two value chains", International Journal of Agile Management Systems, Vol. 1 No. 3, pp. 169-76.

Gonzalez-Benito, J. and Spring, M. (2000), "JIT purchasing in the Spanish auto components industry: implementation patterns and perceived benefits", International Journal of Operations \& Production Management, Vol. 20 No. 9, pp. 1038-61.

Gonzalez-Benito, J., Suaraz-Gonzalez, I. and Spring, M. (2000), "Complementarities between JIT purchasing practices: an economic analysis based on transaction costs", International Journal of Production Economics, Vol. 67 No. 3, pp. 279-93.

Gosain, S., Malhotra, A. and El Sawy, O.A. (2005), "Coordinating for flexibility in e-business supply chains”, Journal of Management Information Systems, Vol. 21 No. 3, pp. 7-45.

Graves, S.C. and Tomlin, B.T. (2003), "Process flexibility in supply chains", Management Science, Vol. 49 No. 7, pp. 907-19.

Handfield, R.B. and Melnyk, S.A. (1998), "The scientific theory-building process: a primer using the case of TQM", Journal of Operations Management, Vol. 16, pp. 321-39.

Harland, C.M., Lamming, R.C. and Cousins, P.D. (1999), "Developing the concept of supply strategy", International Journal of Operations \& Production Management, Vol. 19 No. 7, pp. 650-73.

Jack, E.P. and Raturi, A. (2002), "Sources of volume flexibility and their impact on performance", Journal of Operations Management, Vol. 20, pp. 519-48.

Jordan, W.C. and Graves, S.C. (1995), "Principles on the benefits of manufacturing process flexibility", Management Science, Vol. 41 No. 4, pp. 577-94.

Koste, L.L. and Malhotra, M.J. (1999), "A theoretical framework for analyzing the dimensions of manufacturing flexibility”, Journal of Operations Management, Vol. 18, pp. 75-93.

Krajewski, L., Wei, J.C. and Tang, L.-L. (2005), "Responding to schedule changes in build-to-order supply chains", Journal of Operations Management, Vol. 23, pp. 452-69.

Kumar, V., Fantazy, K.A., Kumar, U. and Boyle, T.A. (2006), "Implementation and management framework for supply chain flexibility", Journal of Enterprise Information Management, Vol. 19 No. 3, pp. 303-19.

Lambert, D.M., Cooper, M.C. and Pagh, J.D. (1998), "Supply chain management: implementation issues and research opportunities", International Journal of Logistics Management, Vol. 9 No. 2, pp. 1-19.

\section{Supply chain flexibility}

969 
IJOPM

29,9

970
Lau, R.S.M. (1996), "Strategic flexibility: a new reality for world-class manufacturing", SAM Advanced Management Journal, Spring, pp. 11-15.

Lummus, R.R., Duclos, L.K. and Vokurka, R.J. (2003), "Supply chain flexibility: building a new model”, Global Journal of Flexible Systems Management, Vol. 4 No. 4, pp. 1-13.

Lummus, R.R., Vokurka, R.J. and Duclos, L.K. (2005), "Delphi study on supply chain flexibility”, International Journal of Production Research, Vol. 43 No. 13, pp. 2687-708.

Lyons, B. and Bailey, S. (1993), "Small subcontractors in UK engineering: competitiveness, dependence and problems", Small Business Economics, Vol. 5, pp. 101-9.

Meredith, J. (1998), "Building operations management theory through case and field research", Journal of Operations Management, Vol. 16, pp. 441-54.

Milner, J.M. and Kouvelis, P. (2005), "Order quantity and timing flexibility in supply chains: the role of demand characteristics", Management Science, Vol. 51 No. 6, pp. 970-85.

Narasimhan, R. and Das, A. (1999), "Manufacturing agility and supply chain management practices”, Production \& Inventory Management Journal, Vol. 40 No. 1, pp. 4-10.

Narasimhan, R. and Das, A. (2000), "An empirical examination of sourcing's role in developing manufacturing flexibilities", International Journal of Production Research, Vol. 38 No. 4, pp. 875-93.

Olhager, J. and West, B.M. (2002), "The house of flexibility: using the QFD approach to deploy manufacturing flexibility", International Journal of Operations \& Production Management, Vol. 22 No. 1, pp. 50-79.

Pérez, M.P. and Sánchez, A.M. (2001), "Supplier relations and flexibility in the Spanish automotive industry", Supply Chain Management, Vol. 6 No. 1, pp. 29-38.

Petroni, A. and Bevilacqua, M. (2002), "Identifying manufacturing flexibility best practices in small and medium enterprises", International Journal of Operations \& Production Management, Vol. 22 No. 8, pp. 929-47.

Sánchez, A.M. and Pérez, M.P. (2005), "Supply chain flexibility and firm performance: a conceptual model and empirical study in the automotive industry", International Journal of Operations \& Production Management, Vol. 25 No. 7, pp. 681-700.

Schmenner, R.W. and Tatikonda, M.V. (2005), "Manufacturing process flexibility revisited", International Journal of Operations \& Production Management, Vol. 25 No. 12, pp. 1183-9.

Semlinger, K. (1993), "Small firms and outsourcing as flexibility reservoirs of large firms", in Grabher, G. (Ed.), The Embedded Firm: On the Socioeconomics of Industrial Networks, Routledge, London.

Sethi, S.P., Yan, H. and Zhang, H. (2004), "Quantity flexibility contracts: optimal decisions with information updates”, Decision Sciences, Vol. 35 No. 4, pp. 691-712.

Slack, N. (1983), "Flexibility as a manufacturing objective", International Journal of Operations \& Production Management, Vol. 3 No. 3, pp. 4-13.

Slack, N. (1987), "The flexibility of manufacturing systems", International Journal of Operations \& Production Management, Vol. 7 No. 4, pp. 35-45.

Spring, M. and Sweeting, R.C. (2002), "Empowering customers: portals, supply networks and assemblers", International Journal of Technology Management, Vol. 23 Nos 1/3, pp. 113-28.

Stevenson, M. and Spring, M. (2007), "Flexibility from a supply chain perspective: definition and review", International Journal of Operations \& Production Management, Vol. 27 No. 7, pp. 685-713. 
Stuart, I., McCutcheon, D., Handfield, R., McLachlin, R. and Samson, D. (2002), "Effective case research in operations management: a process perspective", Journal of Operations Management, Vol. 20, pp. 419-33.

Suarez, F.F., Cusumano, M.A. and Fine, C.H. (1995), "An empirical study of flexibility in manufacturing”, Sloan Management Review, Vol. 37 No. 1, pp. 25-32.

Suarez, F.F., Cusumano, M.A. and Fine, C.H. (1996), "An empirical study of flexibility in printed circuit board assembly”, Operations Research, Vol. 44 No. 1, pp. 223-40.

Tsay, A. (1999), "The quantity flexibility contract and supplier-customer incentives", Management Science, Vol. 45 No. 10, pp. 1339-58.

Tushman, M.L. and O'Reilly, C. (2002), Winning Through Innovation: A Practical Guide to Leading Organizational Change and Renewal, Harvard Business School Press, Boston, MA.

Upton, D.M. (1995), "What really makes factories flexible?", Harvard Business Review, July/August, pp. 74-84.

van Hoek, R.L., Harrison, A. and Christopher, M. (2001), "Measuring agile capabilities in the supply chain", International Journal of Operations \& Production Management, Vol. 21 Nos 1/2, pp. 126-47.

Vickery, S., Calantone, R. and Dröge, C. (1999), "Supply chain flexibility: an empirical study", Journal of Supply Chain Management, Vol. 35 No. 3, pp. 16-24.

Vokurka, R.J. and O'Leary-Kelly, S.W. (2000), "A review of empirical research on manufacturing flexibility”, Journal of Operations Management, Vol. 18, pp. 485-501.

Voss, C., Tsikriktsis, N. and Frohlich, M. (2002), "Case research in operations management", International Journal of Operations \& Production Management, Vol. 22 No. 2, pp. 195-219.

White, A., Daniel, E.M. and Mohdzain, M. (2005), "The role of emergent information technologies and systems in enabling supply chain agility", International Journal of Information Management, Vol. 25, pp. 396-410.

Womack, J.P. and Jones, D.T. (2005), Lean Solutions: How Companies and Customers can Create Value and Wealth Together, Simon \& Schuster, New York, NY.

Yin, R.K. (2003), Case Study Research: Design and Methods, 3rd ed., Sage, London.

\section{Further reading}

Hayes, R.H. (2008), “Operations management's next source of galvanizing energy?”, Production and Operations Management, Vol. 17 No. 6, pp. 567-72.

Smith, P.C. and Laage-Hellman, J. (1992), "Small group analysis in industrial networks", in Axelsson, B. and Easton, G. (Eds), Industrial Networks: A New View of Reality, Routledge, London.

Suri, R. (1999), Quick Response Manufacturing: A Company Wide Approach to Reducing Lead Times, Productivity Press, Portland, OR.

Wu, Z. and Choi, T.Y. (2005), "Supplier-supplier relationships in the buyer-supplier triad: building theories from eight case studies", Journal of Operations Management, Vol. 24 No. 1, pp. 27-52.

\section{Corresponding author}

Mark Stevenson can be contacted at: m.stevenson@lancaster.ac.uk

\footnotetext{
To purchase reprints of this article please e-mail: reprints@emeraldinsight.com
} Or visit our web site for further details: www.emeraldinsight.com/reprints 